\title{
Article
}

\section{Information acquisition differences between experienced and novice time trial cyclists}

Boya, Manhal, Foulsham, Tom, Hettinga, Florentina, Parry, David, Williams, Emily L, Massey, Hollie, Sparks, S Andy, Marchant, David, Ellison, Paul, Bridge, Craig, Mc Naughton, Lars and Micklewright, Dominic

Available at https://clok.uclan.ac.uk/17633/

Boya, Manhal, Foulsham, Tom, Hettinga, Florentina, Parry, David, Williams, Emily L, Massey, Hollie orcid iconORCID: 0000-0002-9793-8702, Sparks, S Andy, Marchant, David, Ellison, Paul et al (2017) Information acquisition differences between experienced and novice time trial cyclists. Medicine and Science in Sports and Exercise, 49 (9). pp. 1884-1898. ISSN 0195-9131

It is advisable to refer to the publisher's version if you intend to cite from the work. http://dx.doi.org/10.1249/MSS.0000000000001304

For more information about UCLan's research in this area go to http://www.uclan.ac.uk/researchgroups/ and search for <name of research Group>.

For information about Research generally at UCLan please go to http://www.uclan.ac.uk/research/

All outputs in CLoK are protected by Intellectual Property Rights law, including Copyright law. Copyright, IPR and Moral Rights for the works on this site are retained by the individual authors and/or other copyright owners. Terms and conditions for use of this material are defined in the policies page. 


\section{Article}

\section{Information acquisition differences of experienced and novice time trial cyclists}

Boya, Manhal, Foulsham, Tom, Hettinga, Florentina, Parry, David, Williams, Emily L, Jones, Hollie S, Sparks, S Andy, Marchant, David, Ellison, Paul, Bridge, Craig, Mc Naughton, Lars and Micklewright, Dominic

Available at http://clok.uclan.ac.uk/18637/

Boya, Manhal, Foulsham, Tom, Hettinga, Florentina, Parry, David, Williams, Emily L, Jones, Hollie S, Sparks, S Andy, Marchant, David, Ellison, Paul et al (2017) Information acquisition differences of experienced and novice time trial cyclists. Medicine and Science in Sports and Exercise. ISSN 0195-9131

It is advisable to refer to the publisher's version if you intend to cite from the work. http://dx.doi.org/10.1249/MSS.0000000000001304

For more information about UCLan's research in this area go to http://www.uclan.ac.uk/researchgroups/ and search for < name of research Group>.

For information about Research generally at UCLan please go to http://www.uclan.ac.uk/research/

All outputs in CLoK are protected by Intellectual Property Rights law, including Copyright law. Copyright, IPR and Moral Rights for the works on this site are retained by the individual authors and/or other copyright owners. Terms and conditions for use of this material are defined in the http://clok.uclan.ac.uk/policies/

\section{CLoK}

Central Lancashire online Knowledge www.clok.uclan.ac.uk

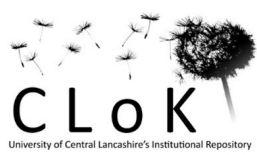




\section{Running Title: Eye-tracking Cycling Time-Trials}

1 Information acquisition differences between experienced and novice time trial cyclists

2

${ }^{1}$ MANHAL BOYA, ${ }^{2}$ TOM FOULSHAM, ${ }^{1}$ FLORENTINA HETTINGA, ${ }^{1}$ DAVID PARRY, ${ }^{4}$ EMILY

4 WILLIAMS, ${ }^{5}$ HOLLIE JONES, ${ }^{3}$ ANDREW SPARKS, ${ }^{3}$ DAVID MARCHANT, ${ }^{3}$ PAUL ELLISON P, $5 \quad{ }^{3}$ CRAIG BRIDGE, ${ }^{3}$ LARS MCNAUGHTON \& ${ }^{1}$ DOMINIC MICKLEWRIGHT.

6

$7 \quad{ }^{1}$ Sport, Performance \& Fatigue Research Unit, University of Essex, UK; ${ }^{2}$ Department of Psychology,

8 University of Essex, UK; ${ }^{3}$ Sport Performance Group, Edge Hill University, UK; ${ }^{4}$ School of Sport, Leeds

9 Beckett University, UK; ${ }^{5}$ School of Psychology, University of Central Lancashire, UK

14 Address for correspondence: Dominic Micklewright PhD, School of Biological Sciences, The University of Essex, Wivenhoe Park, Colchester, Essex, UK. CO4 3SQ; E-mail: dpmick@essex.ac.uk. Tel: +44(0)1206-872869; Fax +44(0)1206-872592.

20 Disclosure of Funding \& Relationships: This study was funded entirely by the University of Essex and

21 no other sources of external funding were used. None of the authors have professional relationships with

22 companies or manufacturers who will benefit from the results of this study. None of the results presented 23 in this study constitute endorsement by the American College of Sports Medicine. 


\section{Running Title: Eye-tracking Cycling Time-Trials}

\section{Abstract}

26 Purpose: To use eye-tracking technology to directly compare information acquisition behavior of

27 experienced and novice cyclists during a self-paced 10 mile $(16.1 \mathrm{~km})$ time-trial. Method: Two groups of novice $(\mathrm{N}=10)$ and experienced cyclists $(\mathrm{N}=10)$ performed a 10-mile self-paced time-trial (TT) on two separate occasions during which a number of feedback variables (speed, distance, power output, cadence, heart rate, and time) were projected within their view. A large RPE scale was also presented next to the projected information and participants. Participants were fitted with a head-mounted eyetracker and heart rate monitor. Results: Experienced cyclists performed both time-trials quicker than novices $\left(\mathrm{F}_{1,18}=6.8, \mathrm{P}=.018\right)$ during which they primarily looked at speed ( 9 of 10 participants $)$ whereas novices primarily looked at distance (6 of 10 participants). Experienced cyclists looked at primary information for longer than novices across the whole time-trial $\left(24.5 \pm 4.2 \%\right.$ vs. $34.2 \pm 6.1 \%, \mathrm{t}_{18}=4.2$,

$36 \mathrm{P}<0.001)$ and less frequently than novices during the last quarter of the time-trial $\left(49 \pm 19 \mathrm{vs} .80 \pm 32, \mathrm{t}_{18}=-\right.$ 2.6, $\mathrm{P}=0.009)$. The most common combination of primary and secondary information looked at by experienced cyclists was speed and distance respectively. Looking at ten different primary-secondary feedback permutations, the novices were less consistent than the experienced cyclists in their information acquisition behavior. Conclusion: This study challenges the importance placed on

41 knowledge of the endpoint to pacing in previous models, especially for experienced cyclists for whom distance feedback was looked at secondary to, but in conjunction with, information about speed. Novice cyclists have a greater dependence upon distance feedback, which they look at for shorter and more

44 frequent periods of time than the experienced cyclists. Experienced cyclists are more selective and 45 consistent in attention to feedback during time-trial cycling.

46 Keywords: Performance; Pacing; Cycling; Vision; Cognition; Decision 


\section{Running Title: Eye-tracking Cycling Time-Trials}

\section{Introduction}

(Paragraph 1) It is important for athletes to employ their available energy effectively to perform optimally and avoid fatigue during exercise, so that "all energy stores are used before finishing a race, but not so much that a meaningful slowdown occurs." $(8,18,29)$ Pacing strategy is an essential aspect of competitive prolonged athletic performance and refers to the variation of speed during an event by regulating the rate of energy expenditure $(18-21,28)$. Where completion time is the measure of success, pacing strategy has an influence over success in events lasting longer than 60 seconds (1).

(Paragraph 2) Several factors are known to influence the pacing strategy that an athlete adopts including the duration of the event (8), presence of a competitor (7,57), environmental conditions (41), previous experience (35), perceptions of exertion (49), and the availability and veracity of performance feedback information $(14,36)$. Previous models of pacing place a lot of emphasis on an athlete's awareness of changes to the internal physiological state of their body, experienced as perceived exertion, in relation to their progress towards the endpoint as informed through various forms of feedback. According to Teleoanticipation Theory (50) and later on the Central Governor Model (40), a 'central governor' anticipates exercise and presets a pacing strategy based on the end-point or duration of exercise. In a more recent manifestation of Central Governor Model, more complex informationprocessing mechanisms have been proposed in which rate of change of perceived exertion is evaluated in the light of expected duration or distance of an event and modified through appropriate alternations in pace (48). The Psychobiological Model similarly supports the notion of effort-related decisions about pace in the context of event duration, but argues that such decisions are entirely conscious and that subconscious processes, such as those proposed by the Central Governor Model, are inapposite (34). The linear relationships found between RPE and the proportion of completed event, are such that the RPE gradient was found to peak in coincidence with the expected endpoint $(15,19,31)$. 


\section{Running Title: Eye-tracking Cycling Time-Trials}

71 (Paragraph 3) In an attempt to factor for varying uncertainty about pace during endurance events, a model has been specified whereby risk is expressed as the proportion of the remaining task multiplied by their momentary RPE, a variable the authors refer to as hazard score (9). An appealing feature of the hazard score model is that the further an athlete progresses, the lower hazard score becomes, thus explaining how athletes are sometimes able to risk performing very intense spurts of energy towards the end of an event when the risk of not-completing as a consequence of doing so is relatively low. An alternative model proposed that pacing decisions are based upon the estimated time that present power output can be maintained, as judged against the duration or length of the task (23). More recent suggestions of how pace is regulated have drawn on the decision-making literature (42) and the interdependence of perception and action in attempting to account for pacing behavior in environmentally complex situations (45).

(Paragraph 4) Whatever theory of pacing is subscribed to, all emphasize knowledge of proximity to the endpoint as a key determinant of pacing strategy. However, the importance placed on endpoint knowledge in pacing models is based on experimental evidence that was collected using limited indirect observation methods where participants have been deceived about, or deprived of, progression or performance feedback information (30). A number of studies have used false feedback about distance or time to understand the importance of feedback and the use of knowledge during exercise. Studies have found that deceiving athletes about the duration of exercise, by providing false or no knowledge about the exercise endpoint, leads to increased RPE and a different pacing strategy caused by an incorrect allocation of physiological resources $(3,12)$. Experience of using blind, true and false performance feedback has also been found to provoke different types of learnt pacing strategies (38).

(Paragraph 5) Feedback deception and blinding experimental methods have been the dominant approaches used to understand how athletes use information to pace themselves. Deductions about the 


\section{Running Title: Eye-tracking Cycling Time-Trials}

94 significance and role of particular types of performance information are made based upon what happens to pace if that information is altered or removed. The underlying logic is that if, after altering or removing a particular source of information pacing or performance worsens, then it can be inferred that that information source has an important contributory role. It has been this approach that has led to the emphasis placed on knowledge of the endpoint in various pacing models.

99 (Paragraph 6) There are several limitations to this information-knockout approach. The first is the focus 100 on singular sources of information and the lack of investigative sophistication in understanding how 101 athletes interpret various sources of information in conjunction with each other. For example, the 102 importance athletes place on speed or power information to make pacing decisions could potentially vary 103 according to how much time or distance has elapsed, or according to environmental conditions or 104 competitor behavior. A further, but related, limitation is that knockout and deception studies have not 105 investigated within-trial changes in the emphasis placed on certain types of feedback. For example, 106 potentially an athlete may be more concerned with average speed in the first half of a race and then 107 become more interested in elapsed time or distance towards the end of an event. The final limitation is 108 the inability to understand individual differences in feedback preferences, which could vary according to 109 past experience or the outcome measure by which they appraise their achievement success. A threat to 110 the validity of previous pacing models is the reliance on limited deception and blinding methods, which 111 necessitated indirect interpretation regarding the importance of endpoint awareness as a determinant of 112 athletic pace. It is this point that the present study intended to redress.

113 (Paragraph 7) A more direct method of measuring what information athletes seek and use during self114 paced exercise will greatly improve our understanding of pacing decisions and, to our knowledge, this

115 have never been achieved. In one study the frequency with which children looked at elapsed time during 116 a time-limited run was measured from a video recording and it was found that they looked at the watch 


\section{Running Title: Eye-tracking Cycling Time-Trials}

117 more often towards the end of the run (6). While the methods of measuring information acquisition in

118 this study were quite basic, eye-tracking technology does provide a more sophisticated method of

119 directly measuring what information athletes look at during self-paced exercise. Unlike previous

120 deception and information-knockout studies, the precision with which information acquisition behavior

121 can be measured using eye-tracking technology is able to overcome the limitations of deception studies

122 discussed earlier. Importantly, eye-tracking enables detailed information to be gathered about how

123 athletes acquire information in dynamic and conjunctive ways during an exercise trial, as well as how

124 they learn to use information differently with experience to pace themselves.

125 (Paragraph 8) The use of eye-tracking technology in sport is a powerful method (11) that has enabled 126 researchers to develop better insights about perceptual-cognitive mechanisms of sport performance (24, 127 33). Mobile eye-tracking technology has proven especially versatile in allowing researchers to collect 128 data in many different sports domains where performance is dependent upon the ability perceive and 129 process complex information in often fast moving environments. In such situations, the visual is the 130 dominant mode of sensory feedback in the perceptual-action coupling (32), a system in which attention 131 to external cues enables the kind of adaptive movements required for the successful performance of 132 motor tasks such as catching or striking a ball. In the context of cycling, eye-tracking has provided 133 useful insights about the role of visual behaviour in balance and steering $(51,53)$ but has not been used 134 to understand information pick-up as part of the perceptual-action processes in regulating pace (45). 135 Eye-tracking technology has also provided considerable insights about differences in perceptual136 cognitive mechanisms between expert and novice performers $(24,55)$, and this approach has great 137 potential in developing a better understanding of information acquisition and decision-making during 138 self-paced cycling. Generally, previous research has suggested that experts across many sports domains 139 tend to look at task-relevant information less frequently and for less time than novices $(24,27)$. This has 


\section{Running Title: Eye-tracking Cycling Time-Trials}

140 a relevance to pacing theory because it raises the question of whether differences exist between expert

141 and novice cyclists about what information feedback they consider to be task relevant, and whether

142 differences exist in how frequently they refer to such information and for how long.

143 (Paragraph 9) While we acknowledge that the use of eye-tracking technology is fairly common-place in 144 sport domains and expertise research, the present study used eye-tracking technology in an original way 145 to better understand information acquisition and pacing behaviour in cyclists. The purpose was, for the 146 first time, to directly measure what information cyclists look at while performing a time-trial, and to 147 compare the information-acquisition strategies of novice and experienced cyclists. We hypothesized that 148 experienced cyclists would look at fewer sources of information, and would seek out information less 149 frequently compared to novices.

\section{Methods}

Participants

152 (Paragraph 10) Experienced $(\mathrm{n}=10)$ and novice male cyclists $(\mathrm{n}=10)$ were recruited for this study from 153 the University of Essex and local cycling clubs. Mean \pm 1SD age, stature and body mass for the 154 experienced cyclists was $38.6 \pm 11.3$ years, $176.6 \pm 6.9 \mathrm{~cm}$ and $74 \pm 9.4 \mathrm{~kg}$ for the experienced cyclists, 155 and for the novice cyclists was $36.1 \pm 9.9$ years, $178.5 \pm 6.7 \mathrm{~cm}$ and $80.2 \pm 8.7 \mathrm{~kg}$. The experienced 156 cyclists were recruited from local cycling clubs and had participated in competitive $16.1 \mathrm{~km}$ time-trials 157 for an average of $14.1 \pm 13$ years. During the 6 months preceding the study, the experienced cyclists had 158 on average trained each week on $4.7 \pm 1.1$ occasions for a total of $8.5 \pm 2.1$ hours. The novice cyclists 159 were recruited from the University of Essex staff and students and, although they could all ride a bicycle, 160 they had never trained for, or participated in competitive cycling events of any kind. In an attempt to 161 control for fitness, only physically active individuals were recruited to the novice group who had on 162 average trained each week on $2.8 \pm 0.8$ occasions for a total of $4.6 \pm 1.1$ hours across a range of different 


\section{Running Title: Eye-tracking Cycling Time-Trials}

163 sports that did not involve cycling. Each participant provided written informed consent to take part in

164 this study, which was approved by the University of Essex ethics committee.

Design

166 (Paragraph 11) A two-way mixed experimental design (experience-by-segment) was used in which we

167 compared pace, performance and visual information acquisition between novice and experienced cyclists 168 (between-subjects experience factor) during a $16.1 \mathrm{~km}$ cycling time-trial every $4 \mathrm{~km}$ (within-subjects 169 segment factor). All participants performed a $16.1 \mathrm{~km}$ familiarization time trial (TT $\mathrm{FAM}$ ) and then had a 170 recovery period of 5 to 10 days before completing the $16.1 \mathrm{~km}$ experimental time-trial $\left(\mathrm{TT}_{\mathrm{EXP}}\right)$. During 171 each time-trial completion time (s), speed $\left(\mathrm{km} \cdot \mathrm{hr}^{-1}\right)$, power output $(\mathrm{W})$, distance $(\mathrm{km})$, pedaling cadence $172\left(\right.$ r. $\left.\mathrm{min}^{-1}\right)$ and heart rate $\left(\mathrm{b} \cdot \mathrm{min}^{-1}\right)$ was measured. RPE was recorded every $4 \mathrm{~km}$. Participants wore a 173 monocular eye-tracking device for familiarization purposes during $\mathrm{TT}_{\mathrm{FAM}}$ and then to measure the type, 174 duration and frequency of information they looked at during $\mathrm{TT}_{\mathrm{EXP}}$.

\section{Procedure}

176 (Paragraph 12) Before each time-trial participants were asked to refrain from ingesting caffeine for at 177 least 6 hours, alcohol for 24 hours and food for 2 hours prior to testing. Participants were also asked not 178 to train or engage in heavy physical work for 24 hours before testing. On the first laboratory attendance 179 each participant had their body mass and stature measured and was briefed as to the requirements of the 180 trial but not the purpose of the study. Participants also completed a short training history questionnaire.

181 After all tests had been completed, participants were debriefed about the purpose of the study.

\section{Cycling Ergometry and Video Simulation}

183 (Paragraph 13) All cycling tests were performed on a Velotron (3D) Racer Mate ergometer with

184 RealVideo simulation software (Racermate, Seattle). The $16.1 \mathrm{~km}$ time-trial duration was selected as this 185 is a common format used in the UK and one which the experienced cyclists used in this study were most 


\section{Running Title: Eye-tracking Cycling Time-Trials}

accustomed. All cycling tests were performed at the same time of day \pm one hour to control for circadian variation in outcome measures. Prior to each time-trial, participants performed a standardized 5-minute self-paced warm-up. Participants were instructed to complete the time-trial in the fastest possible time.

They were not provided with any information acquisition or pacing guidance.

(Paragraph 14) During each time-trial, a RealVideo simulated cycling course was projected onto a wall in front of and slightly offset to the right of the cycling. The projected video footage was coupled in a multiplicative way to the cyclists' actual power output such that any alteration in speed was instantly represented on the screen. Notwithstanding minor projector repositioning variances, the projected screen size was $2.1 \mathrm{~m}$ wide by $1.5 \mathrm{~m}$ high with the bottom border of the projection running $1 \mathrm{~m}$ above and parallel to the floor. The cycle ergometer was positioned such that the handlebar stem riser was $3 \mathrm{~m}$ perpendicular to the plane of the screen which itself was offset to the right of the natural forward field of vision of the cyclists with a vector displacement of $8^{\circ}$ at $3.03 \mathrm{~m}$ for the left border of the projection and $40^{\circ}$ at $3.91 \mathrm{~m}$ for the right border (visual $\operatorname{arc} 32^{\circ}$ ). Offsetting the screen in this way required participants to rotate their neck to look at the projected information, thus adding confidence that the eye-tracking measurements constituted deliberate attempts to acquire information, rather than information glances just because it happened to fall naturally within participants forward field of vision.

(Paragraph 15) Incorporated into the projection beneath the simulated time-trial video, were five fields of real-time feedback information which, presented from left to right, were speed $\left(\mathrm{km} \cdot \mathrm{hr}^{-1}\right)$, elapsed distance $(\mathrm{km})$, power output $(\mathrm{W})$, pedaling cadence $\left(\mathrm{r} \cdot \mathrm{min}^{-1}\right)$ and heart rate $\left(\mathrm{b} \cdot \mathrm{min}^{-1}\right)$. The row of five feedback information fields were $0.375 \mathrm{~m}$ above and parallel to the bottom border of the projection or $1.375 \mathrm{~m}$ above the floor. The vector displacement of the center of each information field from the handlebar stem riser was speed $\left(9.5^{\circ}, 3.04 \mathrm{~m}\right)$, elapsed distance $\left(18.1^{\circ}, 3.16 \mathrm{~m}\right)$, power output $\left(26.0^{\circ}\right.$, $3.34 \mathrm{~m})$, pedaling cadence $\left(32.9^{\circ}, 3.57 \mathrm{~m}\right)$ and heart rate $\left(38.9^{\circ}, 3.86 \mathrm{~m}\right)$. Elapsed time (min:sec) was 


\section{Running Title: Eye-tracking Cycling Time-Trials}

209 displayed above the heart rate field $\left(3.0^{\circ}, 0.2 \mathrm{~m}\right)$. The block size of individual characters within each

210 field was $4.5 \mathrm{~cm}$ high by $2.9 \mathrm{~cm}$ wide. Angular separation of the information fields was at its most acute

$2113^{\circ}$ (elapsed time - heart rate) and at its least acute $8.6^{\circ}$ (elapsed distance - speed), well beyond the

212 manufacturer-defined eye-tracker spatial resolution of $0.1^{\circ}$ and gaze position accuracy within the nearest

213 degree. The size and separation of the projected information blocks therefore facilitated clear

214 differentiation in eye-tracker measurements as later described. An A0 sized RPE scale was also

215 displayed to the left of the projector screen.

216 Psychophysiological Measures

217 (Paragraph 16) Heart rate (HR) was recorded during both cycling time-trials every (120) milliseconds 218 using a chest strap Polar Accurex Plus heart rate monitor (Polar Electro. Kempele, Finland) connected 219 via wireless to the Velotron software. Average HR was calculated every $4 \mathrm{~km}$. Participants were asked to 220 provide an overall rating of perceived exertion every $4 \mathrm{~km}$ using the Borg 6-10 RPE scale (5). All 221 subjects were familiarised with the RPE scale, which was administered in accordance with published 222 standardised instructions (4).

223 Eye-Tracking and Video Analysis

224 (Paragraph 17) Participants were fitted with a SensoMotoric Instruments SMI iViewX head-mounted 225 monocular eye-tracking device (HED). The system consists of two cameras mounted on a cycling 226 helmet, one that records the eye position of the participant, and a $3.6 \mathrm{~mm}$ wide-angle forward-looking 227 camera that records the scene the participant is looking at. Eye position was recorded at $50 \mathrm{~Hz}$, which 228 was then down-sampled to 25 frames per second for the resulting scene videos. The eye-tracker was 229 calibrated using the participant's left eye in accordance with the manufacturer's instructions by asking 230 participants to fixate a series of markers spanning the area of the display. Calibration accuracy was 231 checked sporadically and at the end of the time trial by asking the participant to fixate points on the 


\section{Running Title: Eye-tracking Cycling Time-Trials}

232 screen and information display. The equipment has a manufacturer-defined spatial resolution of $0.1^{\circ}$ and

233 tests demonstrated that gaze position was accurate to within the nearest degree. The system tracks eye

234 movements using pupil and corneal reflex so that each participant's point of regard can be superimposed

235 onto the recorded scene, thus enabling timed measurements to be made of eye fixations.

236 (Paragraph 18) The eye-tracking videos for $\mathrm{TT}_{\mathrm{EXP}}$ were subsequently reviewed and manually coded by 237 the first author. Manual coding of eye-tracking data remains the state-of-the-art in active tasks, (52) and 238 within-coder comparisons indicated that gaze location could be determined unambiguously. Reliability 239 of similar methods have shown very good inter-rater reliability (22). Due to the relatively low sampling 240 rate of the eye-tracker, saccades could not be automatically detected, but fixations were only coded when

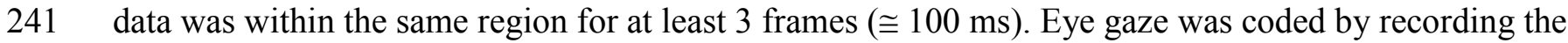
242 start and end frame of each entry into a new region of interest. This allowed us to determine the periods 243 of time spent inspecting each of then eye fixation times were manually recorded in milliseconds against 244 nine predetermined categories. Six of the categories related to information feedback that were speed, 245 elapsed distance, power output, cadence, heart rate and elapsed time. Eye fixation times were also 246 recorded for the rating of perceived exertion and the video simulation of the time-trial course that was 247 projected onto the wall. A final category was created to capture all other objects of regard not 248 corresponding to the other eight categories, for example, when participants looked at the laboratory floor 249 or at laboratory equipment. Fixations of less than 3 frames, blinks and other periods of data loss (e.g. 250 when participants looked at extreme angles) were also included in the 'other' coding category. This 251 procedure allowed detailed coding of point of regard for the whole length of the time trial.

\section{Data Processing and Statistical Analysis}

253 (Paragraph 19) Total gaze time and gaze frequency for each of the nine categories (speed, elapsed 254 distance, power output, cadence, heart rate, elapsed time, video simulation and other) was calculated on 


\section{Running Title: Eye-tracking Cycling Time-Trials}

255 a participant-by-participant basis for the whole time-trial and for each $4 \mathrm{~km}$ segment. Gaze frequency, 256 defined as the number of separate eye fixations for each category, and total gaze time, defined as the 257 accumulated time of all eye fixations for each category, were calculated for each participant across the 258 whole time-trial and for each segment. Total gaze times were then used to determine what information 259 source that each participant looked at for longest accumulated average time (primary), second longest 260 accumulated average time (secondary), third longest accumulated average time (tertiary) and so on until 261 quaternary $\left(4^{\text {th }}\right)$, quinary $\left(5^{\text {th }}\right)$, senary $\left(6^{\text {th }}\right)$, septenary $\left(7^{\text {th }}\right)$, octonary $\left(8^{\text {th }}\right)$ and nonary $\left(9^{\text {th }}\right)$ had all been

262 established. To normalize absolute total gaze times for inter-participant differences in time-trial

263 performance, primary to nonary fixation data were all converted from absolute time (ms) to percentage 264 of time-trial completion time.

265 (Paragraph 20) Time-trial average cycling speed (performance) interactions between experienced and 266 novice cyclists, and between the first and second time-trials was analysed using two-way mixed 267 ANOVAs. Three-way mixed ANOVAs were used to analyse group-by-trial-by-segment interactions in 268 average cycling speed (pace) as well as relative fixation time and gaze frequency for the primary, 269 secondary and tertiary visual categories.

270 (Paragraph 21) For both performance, pace and visual data, significant interactions were followed up 271 using planned post-hoc comparisons between segments using paired-samples $t$ tests for within-group 272 comparisons and independent sample $t$ tests for between-group comparisons. Paired-samples $t$ tests were 273 also used to compare within group comparison and RPE values. All results are expressed as mean (SD) 274 and effect sizes as partial eta squared.

275 Results

276 Time Trial Performance, Heart Rate and RPE 


\section{Running Title: Eye-tracking Cycling Time-Trials}

(Paragraph 22) Two-way mixed ANOVAs revealed the following experience and trial factor outcomes. Average cycling speed: No group-by-trial interaction $\left(\mathrm{F}_{1,18}=2.7, \mathrm{P}=.082, \eta_{\mathrm{p}}{ }^{2}=.16\right)$ but there was a group main effect $\left(\mathrm{F}_{1,18}=6.8, \mathrm{P}=.018, \eta_{\mathrm{p}}{ }^{2}=.27\right)$ and a trial main effect $\left(\mathrm{F}_{1,18}=11.2, \mathrm{P}=.004, \eta_{\mathrm{p}}{ }^{2}=.38\right)$. Completion time: No group-by-trial interaction $\left(\mathrm{F}_{1,18}=2.7, \mathrm{P}=.082, \eta_{\mathrm{p}}{ }^{2}=.16\right)$ but there was a group main effect $\left(\mathrm{F}_{1,18}=6.8, \mathrm{P}=.018, \eta_{\mathrm{p}}{ }^{2}=.27\right)$ and a trial main effect $\left(\mathrm{F}_{1,18}=11.2, \mathrm{P}=.004, \eta_{\mathrm{p}}{ }^{2}=.38\right)$. Average power output: No group-by-trial interaction $\left(\mathrm{F}_{1,18}=0.6, \mathrm{P}=.440, \eta_{\mathrm{p}}{ }^{2}=.03\right)$ but there was a group main effect $\left(\mathrm{F}_{1,18}=10.8\right.$, $\left.\mathrm{P}=.004, \eta_{\mathrm{p}}{ }^{2}=.38\right)$ and a trial main effect $\left(\mathrm{F}_{1,18}=11.6, \mathrm{P}=.003, \eta_{\mathrm{p}}{ }^{2}=.39\right)$. Average pedaling cadence: No group-by-trial interaction $\left(\mathrm{F}_{1,18}=0.1, \mathrm{P}=.740, \eta_{\mathrm{p}}{ }^{2}<.01\right)$ or trial main effect $\left(\mathrm{F}_{1,18}=3.6, \mathrm{P}=.07, \eta_{\mathrm{p}}{ }^{2}=.17\right)$ but there was a group main effect $\left(\mathrm{F}_{1,18}=12.7, \mathrm{P}=.002, \eta_{\mathrm{p}}{ }^{2}=.414\right)$. Average heart rate: No group-by-trial interaction $\left(\mathrm{F}_{1,18}=0.3, \mathrm{P}=.086, \eta_{\mathrm{p}}{ }^{2}<.01\right)$, no group main effect $\left(\mathrm{F}_{1,18}<0.1, \mathrm{P}=.945, \eta_{\mathrm{p}}{ }^{2}<.01\right)$ and no trial main effect $\left(\mathrm{F}_{1,18}=0.2, \mathrm{P}=.646, \eta_{\mathrm{p}}{ }^{2}=.01\right)$. Average RPE: No group-by-trial interaction $\left(\mathrm{F}_{1,18}<0.1, \mathrm{P}=.929\right.$, $\left.\eta_{\mathrm{p}}{ }^{2}<.01\right)$, no group main effect $\left(\mathrm{F}_{1,18}=0.4, \mathrm{P}=.518, \eta_{\mathrm{p}}{ }^{2}=.02\right)$ and no trial main effect $\left(\mathrm{F}_{1,18}=0.9, \mathrm{P}=.361\right.$, $\left.\eta_{\mathrm{p}}{ }^{2}=.05\right)$. Group and trial differences in performance, heart rate and RPE variables are presented in Figure 1A, with post-hoc statistical outcomes indicated for significant differences between novice and experienced cyclists (independent samples t-tests) and between familiarization and experimental timetrials (paired samples t-tests).

\section{Segment Comparisons of Performance, Heart Rate and RPE}

(Paragraph 23) There were no group-by-trial-by-segment interactions or two-way interactions for speed, completion time, power, cadence, heart rate or RPE. Trial main effects were found for speed $\left(\mathrm{F}_{1,18}=12.9, \mathrm{P}=0.002, \eta_{\mathrm{p}}{ }^{2}=.42\right)$, completion time $\left(\mathrm{F}_{1,18}=12.9, \mathrm{P}=0.002, \eta_{\mathrm{p}}{ }^{2}=.42\right)$ and power $\left(\mathrm{F}_{1,18}=11.5\right.$, $\left.\mathrm{P}=0.003, \eta_{\mathrm{p}}{ }^{2}=.39\right)$. Segment main effects were found for speed $\left(\mathrm{F}_{3,54}=4.3, \mathrm{P}=0.009, \eta_{\mathrm{p}}{ }^{2}=.19\right)$, completion time $\left(\mathrm{F}_{3,54}=4.3, \mathrm{P}=0.009, \eta_{\mathrm{p}}{ }^{2}=.19\right)$, power $\left(\mathrm{F}_{3,54}=6.9, \mathrm{P}=0.001, \eta_{\mathrm{p}}{ }^{2}=.28\right)$, heart rate $\left(\mathrm{F}_{3,54}=101, \mathrm{P}<0.001\right.$, $\left.\eta_{\mathrm{p}}{ }^{2}=.85\right)$ and $\mathrm{RPE}\left(\mathrm{F}_{3,54}=518, \mathrm{P}<0.001, \eta_{\mathrm{p}}{ }^{2}=.97\right)$. Group main effects were found for speed $\left(\mathrm{F}_{1,18}=7.9\right.$, 


\section{Running Title: Eye-tracking Cycling Time-Trials}

$\left.300 \mathrm{P}=0.012, \eta_{\mathrm{p}}{ }^{2}=.31\right)$, completion time $\left(\mathrm{F}_{1,18}=7.9, \mathrm{P}=0.012, \eta_{\mathrm{p}}{ }^{2}=.31\right)$, power $\left(\mathrm{F}_{1,18}=10.8, \mathrm{P}=0.004, \eta_{\mathrm{p}}{ }^{2}=.38\right)$

301 and cadence $\left(\mathrm{F}_{1,18}=12.7, \mathrm{P}=0.002, \eta_{\mathrm{p}}{ }^{2}=.414\right)$. Post hoc independent samples t-tests found experienced

302 cyclists were faster than novices during every time-trial segment, in both $\mathrm{TT}_{\mathrm{FAM}}$ and $\mathrm{TT}_{\mathrm{EXP}}$. Group and

303 segment differences in pace with post-hoc outcomes are presented in Figure 1B for TT $_{\mathrm{FAM}}$ and in Figure

$3041 \mathrm{C}$ for $\mathrm{TT}_{\mathrm{EXP}}$. Mean and standard deviation data for speed, completion time, power, cadence, heart rate

305 and RPE are given in Table 1 for each group, time-trial and segment along with post hoc statistical test

306 outcomes.

307 Whole Time-Trial Eye-Tracking Outcomes: Total Gaze Duration and Gaze Frequency

308 (Paragraph 24) Novice and Experienced mean total gaze duration data for primary through to nonary

309 points of regard were calculated over the full $16.1 \mathrm{~km}$ for $\mathrm{TT}_{\mathrm{EXP}}$ and are presented in Figure $2 \mathrm{~A}$. A two-

310 way mixed ANOVA found a group-by-point of regard interaction for total gaze duration (\% time-trial

311 duration), $\mathrm{F}_{8,144}=10.9, \mathrm{P}<0.001, \eta_{\mathrm{p}}{ }^{2}=.38$. Independent-samples post-hoc $\mathrm{t}$-tests revealed that experienced

312 cyclists looked at primary points of regard for longer than novices during $\operatorname{TT}_{\mathrm{EXP}}(34.2 \pm 6.1 \% \mathrm{vs}$.

$\left.31324.5 \pm 4.2 \%, \mathrm{t}_{18}=-4.2, \mathrm{P}<0.001, \eta^{2}=0.49\right)$. Other experienced vs. novice post-hoc outcomes for total gaze

314 time are represented in Figure 2A.

315 (Paragraph 25) The frequency of which novice and experienced participants looked at primary through

316 to nonary points of regard was counted overall for TT EXP and is presented in Figure 2B. A two-way

317 mixed ANOVA found a group-by-point of regard interaction for gaze frequency, $\mathrm{F}_{8,144}=2.2, \mathrm{P}=0.03$,

$318 \eta_{\mathrm{p}}{ }^{2}=0.11$. Independent-samples post-hoc t-tests revealed that experienced cyclists looked at information

319 less frequently than novices (Figure 2B).

320 Time-Trial Segment Eye-Tracking Outcomes: Total Gaze Duration and Frequency

321 (Paragraph 26) Segment changes in gaze duration and gaze frequency were analysed using two-way

322 mixed ANOVAs for primary, secondary and tertiary points of regard. Group main effects were found for 


\section{Running Title: Eye-tracking Cycling Time-Trials}

total gaze duration for the primary point of regard $\left(\mathrm{F}_{1,18}=16, \mathrm{P}<0.001, \eta \mathrm{P}^{2}=0.47\right)$ and the secondary point of regard $\left(\mathrm{F}_{1,18}=6.7, \mathrm{P}=0.02, \eta_{\mathrm{P}}{ }^{2}=0.27\right)$ but not the tertiary point of regard. No segment main effects or segment-by-group interactions were found for primary, secondary or tertiary points of regard (Figures 3A-C). For gaze frequency of the primary point of regard a segment-by-group interaction was found $\left(\mathrm{F}_{3,54}=3.4, \mathrm{P}=0.02, \eta_{\mathrm{P}}^{2}=0.16\right)$ and a segment main effect $\left(\mathrm{F}_{3,54}=2.8, \mathrm{P}=0.05, \eta_{\mathrm{P}}^{2}=0.13\right)$ but not a group main effect. For gaze frequency of the secondary point of regard only a group main effect was found $\left(\mathrm{F}_{1,18}=8.9, \mathrm{P}=0.008, \eta \mathrm{P}^{2}=0.33\right)$ with no segment main effect or segment-by-group main effect. There were no gaze frequency interactions or main effects for the tertiary point of regard (Figures $4 \mathrm{~A}-\mathrm{C}$ ).

(Paragraph 27) Group-by-trial-by-segment analysis for quaternary through to nonary points of regard are excluded from this article for the sake of brevity, owing to the large amount of statistical data. We also believe that the analysis of gaze data beyond the three most looked at points of regard are unlikely to yield significant insights about systematic perceptual patterns, pacing and performance.

\section{Primary-Secondary Point of Regard Combinations}

(Paragraph 28) Data is presented in Table 2 shows the combination of primary and secondary points of regard that participants looked at across the entire experimental time-trial and on a segment-by-segment basis. Individual participant data is present in an attempt to convey the complex, yet in some instances similar, patterns of information that participants looked at during the time-trial. Seven primarysecondary point of regard combinations were observed for the novice group during $\mathrm{TT}_{\mathrm{EXP}}$, whereas the experienced cyclists exhibited only three primary-secondary point of regard combinations.

(Paragraph 29) Mann-Whitney non-parametric comparisons were made between novices and experienced cyclists in the number of primary points of regard they looked at in each segment and the number of times they switched what they primarily looked at between segments. Results showed a lower number of different primary points of regard by experienced cyclists compared to novices during TTEXP 


\section{Running Title: Eye-tracking Cycling Time-Trials}

$346(1.7 \pm 0.8$ vs. $2.8 \pm 0.9, U=19.5, Z=-2.41, P=0.008)$. From segment to segment, the number of times

347 participants switched to a different primary point of regard was lower among the experienced cyclists

348 compared to novices ( $1.3 \pm 1.4$ vs. $2.3 \pm 0.9, \mathrm{U}=31, \mathrm{Z}=-1.53, \mathrm{P}=0.064)$. Primary point of regard and switch

349 data is given in Table 2.

350 (Paragraph 30) A two-way mixed ANOVA found a group-by-segment interaction for the percent 351 dominance of the primary point of regard in the primary-secondary combination, $\mathrm{F}_{3,54}=4.4, \mathrm{P}=0.05$, $352 \eta_{\mathrm{p}}{ }^{2}=.20$, a group main effect, $\mathrm{F}_{1,18}=9.4, \mathrm{P}=0.007, \eta_{\mathrm{p}}{ }^{2}=.34$, but no segment main effect, $\mathrm{F}_{3,54}=0.4, \mathrm{P}=0.52$, $353 \eta_{\mathrm{p}}{ }^{2}=.02$. Independent-samples post-hoc t-tests revealed that dominance of the primary point of regard in 354 the primary-secondary combination was greater among experienced cyclists compared to novices for the $3550-4 \mathrm{~km}$ segment $\left(63.8 \pm 7.8 \%\right.$ vs. $\left.53.6 \pm 3.2 \%, \mathrm{t}_{18}=-3.8, \mathrm{P}<0.001, \eta^{2}=0.45\right)$, the $4-8 \mathrm{~km}$ segment $356\left(61.7 \pm 8.0 \%\right.$ vs. $\left.56.2 \pm 4.3 \%, \mathrm{t}_{18}=-1.9, \mathrm{P}=0.036, \eta^{2}=0.17\right)$, the $8-12 \mathrm{~km}$ segment $(63.4 \pm 6.5 \%$ vs. $\left.35756.6 \pm 5.3 \%, \mathrm{t}_{18}=-2.6, \mathrm{P}=0.01, \eta^{2}=0.27\right)$ but not the final $12-16.1 \mathrm{~km}$ segment $(59.8 \pm 7.6 \% \mathrm{vs} .60 .1 \pm 7.8 \%$, $\left.358 \mathrm{t}_{18}=0.1, \mathrm{P}=0.93, \eta^{2}<0.01\right)$. Group-by-trial-by-segment primary dominance values are given in Table 2.

\section{Discussion}

360 (Paragraph 31) This study was the first to make direct measurements of information-acquisition 361 behavior among time-trial cyclists and constitutes a significant step forward in our understanding of 362 endurance exercise pacing mechanisms. It seems that patterns of information acquisition during a self363 paced cycling time trials are very complex and that pacing behavior is not necessarily universally 364 informed by the integration of endpoint awareness and perceived exertion, as previous models have 365 argued $(9,15,20,23,40,46,48,50)$. This is because we observed that, firstly, cyclists refer to different 366 types of information according to their experience, with experienced cyclists primarily looking at speed 367 and novices primarily looking at distance (Fig 2A). Secondly, experienced cyclists appear to be more 368 selective in their information acquisition behavior compared to novices, referring to fewer sources of 


\section{Running Title: Eye-tracking Cycling Time-Trials}

369 information, which they look at for longer (Fig 2A) and less frequently (Fig 2B). Thirdly, novices

370 increased the duration (Fig 3A) and frequency (Fig 4A) of looking at their primary information source

371 during the final segment of the time-trial but experienced cyclists were more constant throughout the

372 trials. Finally, with only four different combinations of primary and secondary information used by the

373 experienced cyclists, there was better commonality in what information they looked at compared to the

374 novices who used seven primary-secondary information combinations (Table 2). Our finding that

375 experienced cyclists refer to task-relevant information less often is consistent with a meta-analysis of

376 eye-tracking studies of expert performers (24), yet our findings that experienced cyclists fixate for longer

377 than novices is not consistent with the meta-analysis (24). This maybe because, as acknowledged by the

378 authors of the meta-analysis, the type of sport task may moderate expert-novice differences in visual

379 behavior compared to other domains (24). Experienced cyclists also tended to stick to a primary

380 information source throughout the time-trial, whereas novices switched the type of information they

381 primarily looked at between segments much more often (Table 2). We are not suggesting that endpoint

382 awareness is not important in pacing regulation, clearly it is given how often it featured as either a

383 primary or secondary point of regard in our findings (Table 2). Our argument is that previous pacing

384 models are deficient in accounting for variations in information acquisition that we have found

385 attributable to individual preference, expertise or event segment. It seems that in simulated time-trial

386 cycling experienced cyclists look at speed more than distance, whereas distance feedback appears to be

387 what novices seek out more.

388 (Paragraph 32) An important finding of this study was that experienced and novice cyclists differed in

389 the types of information they looked at during the experimental time trial. The majority of the

390 experienced cyclists ( 9 of 10 participants) tended to look at speed most across the whole time trial. In

391 contrast most novices ( 6 of 10 participants) looked at distance most, noting that a significant number of 


\section{Running Title: Eye-tracking Cycling Time-Trials}

392 novices (4 of 10 participants) chose to primarily look at other information too. In addition to experienced

393 cyclists being more consistent in what information they look at, of note is that they looked at primary

394 information for longer and less frequently.

395 (Paragraph 33) While the eye-tracking data we have collected reveals a lot about how time-trial cyclists 396 acquire information, it does not tell us anything about how the information is integrated and processed, 397 or the decisions they have made. For this, other process-tracing methods such as think aloud protocols, 398 may usefully compliment eye-tracking in the study of decision-making and pacing. This is because that, 399 while eye-tracking technology provides a powerful method for measure information acquisition 400 processes, it reveals nothing about how that information is subsequently processed. Although longer eye 401 fixation times have been linked to greater depth of processing $(16,26,43,44)$, rather than assuming this to 402 be the case in future pacing studies, it would be preferable to use eye-tracking in conjunction with think 403 aloud protocols to directly capture information processes. Nevertheless, the results of the present study 404 so highlight differences in information acquisition between novice and experienced time-trial cyclists 405 that bring to question the common information-processing mechanisms put forward by previous pacing 406 models $(9,15,18,23,31,34,40,42,45,50)$. In particular, the assumption in previous pacing models that the 407 integration of endpoint awareness with perceived exertion is the primary and universal driver of pacing 408 decisions, regardless of athletic experience or individual feedback preferences. It may be that decision409 making among experienced cyclists was different to novices and indeed different between individuals 410 which resulted in a need to seek out more varied sources of information. This is consistent with the idea 411 that individuals use information in an adaptive way according to the perceived demands of a situation or 412 problem (25). Thus, it could be that distance information is still important to experienced cyclists but, 413 owing to their previous experience, they are able to process and integrate such information much more 414 quickly and thus do not need to look at it quite so often or for so long. Since the experienced participants 


\section{Running Title: Eye-tracking Cycling Time-Trials}

415 were experienced at performing the $16.1 \mathrm{~km}$ time-trial format, it is also quite likely that their need to

416 refer to distance information was less than novices unaccustomed to cycling such a distance. The extent

417 to which information acquisition differences between experienced and novice cyclists are attributable to

418 distance familiarity, is something that could be tested by using the same experimental protocol but with

419 an unfamiliar time trial distance. While it is well established that experience influences pacing strategy

$420(19,35,38)$, our findings further show that information acquisition strategies accompanying pacing

421 behavior also vary with previous experience.

422 (Paragraph 34) As expected the experienced cyclists completed both time-trials faster than the novices, 423 with both groups exhibiting a mostly constant pace throughout. Owing to imperfect fitness matching 424 between the novice and experienced cyclists, we cannot conclude that that time-trial performance 425 differences between the groups was exclusively due to experience differences. While in future studies 426 greater effort should be made to measure associations between moment-by-moment change in gaze and 427 pacing time-series data (37), in this study we have limited our analysis to detecting concomitant changes 428 in gaze and pace at a segment-by-segment level. What our data clearly shows is that, whatever type of 429 information is preferred as the primary reference, the experienced cyclists looked at it for longer than the 430 novices but less frequently. As previously discussed, this is broadly consistent with previous expertise 431 literature (24). During the second time-trial the experienced cyclists increased the relative amount of 432 time they spent looking at the primary information source from 30 to $35 \%$ showing that they became 433 more selective in what information they referred to. The shallower curves presented in Figure $2 \mathrm{~A}$ also 434 shows that novices tended to distribute their attention across a number of different information sources, 435 spending more time looking at quaternary to octonary sources of information compared to the 436 experienced cyclists. The notion that experienced cyclists are more selective in what feedback they look 437 at is also consistent with previous expertise literature $(24,33)$ and is supported in a number of ways. In 


\section{Running Title: Eye-tracking Cycling Time-Trials}

438 the first three segments, the experienced cyclists on average spent between $5-10 \%$ longer than novices

439 looking at the primary point of regard. It was only in the last segment of the time-trials from $12-16.1 \mathrm{~km}$,

440 that the novices increase both the amount of time and the frequency with which they look at the primary

441 information source close to that of the experienced cyclists. The increased information acquisition

442 behavior towards the end of the time-trial is consistent with the behavior observed in children during a

443 self-paced running task (6), further supporting the idea that feedback-dependency is more strongly

444 associated with proximity to the end-point among inexperienced athletes compared to experienced

445 athletes.

446 (Paragraph 35) The data from our study indicates greater consistency in experienced cyclists' approach

447 to information acquisition both in terms in inter- and intra-participant behavior. Inter-participant

448 consistency is evident in the data showing that 9 of 10 experienced cyclists chose to primarily look at

449 speed. Even when combinations of information sources are considered, experienced cyclists consistency

450 chose either speed-distance (5/10), speed-other (2/10) or speed-power $(2 / 10)$ as the combination of

451 primary and secondary points of regard. In fact, the experienced cyclists only exhibited four different

452 primary-secondary information combinations, whereas seven different primary-secondary combinations

453 were observed among the novices (Table 2).

454 (Paragraph 36) Greater intra-participant consistency among the experienced cyclists is apparent owing 455 to the fact that on a segment-by-segment basis, the modal primary-secondary combinations were speed456 distance and speed other, but for the novices it was often not possible to specify a modal combination 457 because the primary-secondary permutations were so varied. On average novices used 2.3 different 458 primary information sources across the four segments compared to 1.5 for the experienced cyclists. 459 Novices also tended to switch primary information sources between segments more frequently than the 460 experienced cyclists as indicated in Table 2. 


\section{Running Title: Eye-tracking Cycling Time-Trials}

461 (Paragraph 37) The primary-secondary combination data presented in Table 2 is also interesting

462 because it highlights that distance is still an important reference source to experienced cyclists, but only

463 secondary to and in combination with speed. In contrast, distance feedback appears to be the most

464 dominant type of information they refer to in combination with many other types of secondary

465 information. A lot of emphasis has been placed the role of the endpoint in influencing pacing

$466(2,3,9,15,19,31,34,40,46,50)$ support for which being found in a number of studies where deception or

467 blinding methods have been used $(3,12,30,38)$. However, our study shows that the importance placed on

468 knowledge of the end-point may be overstated in most pacing models and that, knowledge of the

469 endpoint may in fact be a secondary to information about speed in informing the actions of experienced

470 cyclists. Another interesting outcome of this study is that perceived exertion did not feature in the

471 primary-secondary information acquisition combinations for any of the participants (Table 2), and that,

472 whether experienced or novice cyclists, all looked at least three other sources of information in

473 preference to the 6-20 RPE scale (Fig 2). That does not mean perceived exertion is not an important

474 factor in pacing decisions as predicted by many of the previous models. It does however, highlight to

475 methodological complexities of investigating pacing decisions in terms of the acquisition and utilization

476 of external referents, which can be easily observed using methods like eye-tracking, and the integration

477 of internal bodily referents such as perceived exertion, which cannot be directly observed. This particular

478 problem warrants innovative research using process-tracing methods of the kind described in much more

479 detail elsewhere (37).

480 (Paragraph 38) This eye-tracking study has produced some important new data not entirely consistent

481 with previous models of pacing about the attention to, and use of, feedback information. Nevertheless,

482 there are a number of limitations associated with the laboratory-based nature of this experiment and the

483 eye-tracking technology that was used. Cyclists in our study performed simulated time-trials on a static 


\section{Running Title: Eye-tracking Cycling Time-Trials}

cycle ergometer under conditions where certain demands on the visual system were absent, for example those associated with balancing, navigating, negotiating hazards and avoiding collisions as reported elsewhere $(51,53)$. Furthermore, differences between laboratory and real-world visual behavior have been reported in several studies, the most notable findings being more centralized fixations in the real world (17), a tendancy to fixate on closer objects in the laboratory (17), and earlier longer object fixations in the realworld (10). Therefore, it cannot be assumed that, during road-based time-trials, the capacity to attend to performance information will be the same as reported in this experiment since it will compete with, or be interrupted by, other demands placed on the visual system. In the future, with careful configuration of mobile eye-tracking technology, it may be possible to measure the attention to performance information in field-based studies with associated improvements in ecological validity.

(Paragraph 39) Another limitation of this study relates to the link between visual information, decisionmaking processes and pacing behavior. While there is some evidence that what individuals look at is associated with their choices $(16,26,43,44)$, it is unclear whether visual attention influences choice or simply reflects a choice that has been made (44). In our study the issue is further complicated by the difficulties of quantifying a pacing choice, since the method of detecting a meaningful change in pace from either speed or power time-series data is mathematically complex (41). Even if it were possible to precisely identify moments where a decision had been made to increase or decrease pace, decisions to maintain pace would clearly be impossible to detect, as they would not be indirectly reflected in timeseries data. In this study, conclusions about the link between visual attention and pacing decisions, are deduced from the associated changes in vision and pace observed at a segment-by-segment level. In future, greater precision about the association between visual attention to performance information and pace could be investigated by setting up experiments were cyclists are presented with pacing dilemma where their decision to act can be pinpointed in time. 


\section{Running Title: Eye-tracking Cycling Time-Trials}

507 (Paragraph 40) Finally, with regards to information acquisition and decision-making during endurance

508 sport, further consideration is needed regarding fatigue related constraints on visual behavior as

509 predicted in Newell's model (39) because they are often overlooked (56). A relationship between fatigue

510 and declining visual attention was found in one interesting study where increased levels of exertion

511 among biathletes was associated with reduced visual behavior before making a rifle shot (54). Saccadic

512 eye-movements are so fast and energetically efficient (47) that they are less likely to be responsible for

513 such effects compared to high-order cognitive processes such as attention allocation mechanisms which

514 have themselves been found to become fatigued as characterized by reduced capability to suppress

515 irrelevant external cues (13). Such factors are likely to impact information acquisition and decision-

516 making during endurance sport and warrant further investigation.

\section{Conclusions}

518 (Paragraph 41) Although perhaps counterintuitive, this study challenges the degree of importance 519 placed on knowledge of the endpoint to pacing in previous models. This is especially true for 520 experienced cyclists for whom distance feedback was looked at secondary to, but in conjunction with 521 information about speed. Novice cyclists appear to have a greater dependence upon distance feedback, 522 which they look at for shorter and more frequent periods of time than the experienced cyclists.

523 Experienced cyclists are more selective in the information they refer to during a time-trial and they are 524 also more consistent in the combination of primary and secondary information they use, and more 525 consistent between various phases of a time-trial. The difference in information acquisition behavior 526 observed in this study may reflect differences in motivational regulators, with experienced cyclists 527 perhaps focusing more strongly on performing at the fastest speed and novices focusing on completion 528 of the distance. 


\section{Running Title: Eye-tracking Cycling Time-Trials}

529 (Paragraph 42) This study is the first to directly measure cyclists' information acquisition behavior 530 during a time-trial and the data shows that the information athletes attend to and use during self-paced 531 endurance tasks is much more complex than previously assumed and not necessarily dominated by 532 knowledge of the endpoint. The limitations associated with this study are that it cannot be assumed 533 information acquisition would be the same during a road-based time-trial. There are also improvements 534 to the analysis of time-series performance data that are needed to reveal hidden moments where a 535 decision to alter pace has been made so that corresponding gaze behavior can be interrogated with 536 greater precision. Nevertheless, this study has produced some exciting new insights about the 537 information acquisition strategies of experienced and novice cyclists, as well as a new method for 538 investigating visual attention and decision-making during paced exercise.

542 Acknowledgements

543 (Paragraph number 43) This study was funded entirely by the University of Essex and no other sources 544 of external funding were used. None of the authors have professional relationships with companies or 545 manufacturers who will benefit from the results of this study. The results of the study are presented 546 clearly, honestly, and without fabrication, falsification, or inappropriate data manipulation. None of the 547 results presented in this study constitute endorsement by the American College of Sports Medicine. 


\section{Running Title: Eye-tracking Cycling Time-Trials}

\section{References}

1. Albertus Y, Tucker R, Gibson ASC, Lambert EV, Hampson DB, Noakes TD. Effect of Distance Feedback on Pacing Strategy and Perceived Exertion during Cycling. Med Sci Sports Exerc 2005;37(3):461-8.

2. Ansley L, Robson PJ, St Clair Gibson A, Noakes TD. Anticipatory pacing strategies during supramaximal exercise lasting longer than 30 s. Med Sci Sports Exerc 2004;36(2):309-14.

3. Billaut F, Bishop DJ, Schaerz S, Noakes TD. Influence of knowledge of sprint number on pacing during repeated-sprint exercise. Med Sci Sports Exerc 2011;43(4):665-72.

4. Borg G. Borg's perceived exertion and pain scales. Champaign (IL): Human Kinetics. 1998. p. 44 9.

5. Borg G. Perceived exertion as an indicator of somatic stress. Scand J Rehabil Med 1970;2(2):92-8.

6. Chinnasamy C, St Clair Gibson A, Micklewright D. Effect of spatial and temporal cues on athletic pacing in schoolchildren. Med Sci Sports Exerc 2013;45(2):395-402.

7. Corbett J, Barwood MJ, Ouzounoglou A, Thelwell R, Dicks M. Influence of competition on performance and pacing during cycling exercise. Med Sci Sports Exerc 2012;44(3):509-15.

8. DeKoning JJ, Bobbert MF, Foster C. Determination of optimal pacing strategy in track cycling with an energy flow model. J Sci Med Sport 1999;2(3):266-77.

9. DeKoning JJ, Foster C, Bakkum A, et al. Regulation of pacing strategy during athletic competition. PLoS One 2011;6(1):e15863.

10. Dicks M, Button C, Davids K. Examination of gaze behaviors under in situ and video simulation task constraints reveals differences in information pickup for perception and action. Attention Percept Psychophys 2010;72(3):706-20. 


\section{Running Title: Eye-tracking Cycling Time-Trials}

570 11. Discombe RM, Cotterill ST. Eye tracking in sport: A guide for new and aspiring researchers. Sport Exerc Psychol Rev 2015;11:49-58.

572 12. Eston R, Stansfield R, Westoby P, Parfitt G. Effect of deception and expected exercise duration on psychological and physiological variables during treadmill running and cycling. Psychophysiology 2012;49(4):462-9.

13. Faber LG, Maurits NM, Lorist MM. Mental fatigue affects visual selective attention. PloS one 2012;7(10):e48073.

14. Faulkner J, Arnold T, Eston R. Effect of accurate and inaccurate distance feedback on performance

16. Fiedler S, Glöckner A. The dynamics of decision making in risky choice: An eye-tracking analysis. Front Psychol 2012;3(10):1-18.

17. Foulsham T, Walker E, Kingstone A. The where, what and when of gaze allocation in the lab and

18. Foster C, De Koning JJ, Hettinga F, et al. Pattern of energy expenditure during simulated competition. Med Sci Sports Exerc 2003;35(5):826-31.

19. Foster C, Hendrickson KJ, Peyer K, et al. Pattern of developing the performance template. Br J Sports Med 2009;43(10):765-9.

20. Foster C, Schrager M, Snyder AC, Thompson NN. Pacing strategy and athletic performance. Sport Med 1994;17(2):77-85.

21. Foster C, Snyder AC, Thompson NN, Green MA, Foley M, Schrager M. Effect of pacing strategy on cycle time trial performance. Med Sci Sports Exerc 1993;25(3):383-8. 


\section{Running Title: Eye-tracking Cycling Time-Trials}

22. Foulsham T, Walker E, Kingstone A. The where, what and when of gaze allocation in the lab and the natural environment. Vision Res 2011;51(17):1920-31.

23. Garcin M, Coquart J, Salleron J, Voy N, Matran R. Self-regulation of exercise intensity by estimated time limit scale. Eur J Appl Physiol 2012;112(6):2303-12.

24. Gegenfurtner A, Lehtinen E, Säljö R. Expertise differences in the comprehension of visualizations: A meta-analysis of eye-tracking research in professional domains. Educ Psychol Rev 2011;23(4):523-52.

25. Hutchinson JM, Gigerenzer G. Simple heuristics and rules of thumb: Where psychologists and behavioural biologists might meet. Behav Processes 2005;69(2):97-124.

26. Glaholt MG, Reingold EM. The time course of gaze bias in visual decision tasks. Vis cogn $2009 ; 17: 1228-43$.

27. Haider H, Frensch PA. Eye movement during skill acquisition: More evidence for the informationreduction hypothesis. J Exp Psychol Learn 1999;25(1):172-90.

28. Hettinga F, De Koning JJ, Broersen F, Van Geffen P, Foster C. Pacing Strategy and the Occurrence of Fatigue in 4000-m Cycling Time Trials. Med Sci Sport Exerc 2006;38(8):1484-91.

29. Hettinga FJ, De Koning JJ, Meijer E, Teunissen L, Foster C. Biodynamics. Effect of pacing strategy on energy expenditure during a 1500-m cycling time trial. Med Sci Sports Exerc 2007;39(12):2212-8.

30. Jones HS, Williams EL, Bridge C, et al. Physiological and Psychological Effects of Deception on Pacing Strategy and Performance: A Review. Sport Med 2013;43(12):1243-57.

31. Joseph T, Johnson B, Battista R, et al. Perception of fatigue during simulated competition. Med Sci Sports Exerc 2008;40(2):381-6. 


\section{Running Title: Eye-tracking Cycling Time-Trials}

615 32. Le Runigo C, Benguigui N, Bardy BG. Perception-action coupling and expertise in interceptive actions. Hum Movement Sci 2005;24(3):429-45.

617 33. Mann DT, Williams AM, Ward P, Janelle CM. Perceptual-cognitive expertise in sport: A metaanalysis. J Sport Exerc Psychol 2007;29(4):457-78.

34. Marcora SM. Do we really need a central governor to explain brain regulation of exercise performance? Eur J Appl Physiol 2008;104(5):929-31.

35. Mauger AR, Jones AM, Williams CA. Influence of feedback and prior experience on pacing during a 4-km cycle time trial. Med Sci Sports Exerc 2009;41(2):451-8.

36. Mauger AR, Jones AM, Williams CA. The effect of non-contingent and accurate performance feedback on pacing and time trial performance in 4-km track cycling. Br J Sports Med 2009;45(3):225-9.

38. Micklewright D, Papadopoulou E, Swart J, Noakes T. Previous experience influences pacing during $20 \mathrm{~km}$ time trial cycling. Br J Sports Med 2010;44(13):952-60.

631 39. Newell KM. Coordination, control and skill. In: Goodman D, Wilberg RB, Franks IM, editors. Differing Perspectives in Motor Learning, Memory, and Control. Amsterdam: Elsevier Science Publishing; 1985. p. 295-317.

40. Noakes TD, St Clair Gibson A, Lambert E V. From catastrophe to complexity: a novel model of integrative central neural regulation of effort and fatigue during exercise in humans: summary and conclusions. Br J Sports Med 2005;39(2):120-4. 


\section{Running Title: Eye-tracking Cycling Time-Trials}

41. Passfield L, Dietz K, Hopker J, Jobson S. Objective time-binning in exposure variation analysis IMA J Manag 2013;24(3):269-82.

42. Renfree A, Martin L, Micklewright D, St Clair Gibson A. Application of decision-making theory to the regulation of muscular work rate during self-paced competitive endurance activity. Sport Med 2014;44(2):147-58.

43. Shi S, Wedel M, Pieters F. Information acquisition during online decision making: A model-based exploration using eye-tracking data. Manage Sci 2013;59(5):1009-26.

44. Shimojo S, Simion C, Shimojo E, Scheier C. Gaze bias both reflects and influences preference. Nat Neurosci 2003;6(12):1317-22.

45. Smits BLM, Pepping GJ, Hettinga FJ. Pacing and decision making in sport and exercise: The roles of perception and action in the regulation of exercise intensity. Sport Med 2014;44(6):763-75.

46. St Clair Gibson A, Lambert E V, Rauch LHG, et al. The role of information processing between the brain and peripheral physiological systems in pacing and perception of effort. Sport Med 2006;36(8):705-22.

47. Thiele A, Henning P, Kubischik M, Hoffman KP. Neural mechanisms of saccadic suppression. Science 2002;295(5564):2460-2.

48. Tucker R. The anticipatory regulation of performance: the physiological basis for pacing strategies and the development of a perception-based model for exercise performance. Br J Sports Med 2009;43(6):392-400.

49. Ulmer HV. Perceived exertion as a part of a feedback system and its interaction with tactical behaviour in endurance sports. In: Borg G, Ottoson G, editors. The perception of exertion in physical work. London: Palgrave Macmillan; 1986, pp. 317-26. 


\section{Running Title: Eye-tracking Cycling Time-Trials}

659 50. Ulmer H, Schneider A, Neumahr S, Freitag W. Precision of time and velocity estimation as a base 660 of teleoanticipation. Eur J Physiol 1996;431(48):1-5.

661 51. Vansteenkiste P, Cardon G, D’Hondt E, Philippaerts R, Lenoir M. The visual control of bicycle steering: The effects of speed and path width. Accident Anal Prev. 2013;51:222-7.

663 52. Vansteenkiste P, Cardon G, Philippaerts R, Lenoir M. Measuring dwell time percentage from head664 mounted eye-tracking data-comparison of a frame-by-frame and a fixation-by-fixation analysis. $665 \quad$ Ergonomics 2015;58(5):712-21.

666 53. Vansteenkiste P, Zeuwts L, Cardon G, Philippaerts R, Lenoir M. The implications of low quality 667 bicycle paths on gaze behavior of cyclists: A field test. Transport Res F Tr Psychol. 2014;23:81-7. 668 54. Vickers JN, Williams AM, Rodrigues ST, Hillis F, Coyne G. Eye movements of elite biathlon 669 shooters during rested and fatigued states. J Sport Exerc Psychol 1999;21:S116.

670 55. Williams AM, Ericsson KA. Perceptual-cognitive expertise in sport: Some considerations when applying the expert performance approach. Human Mov Sci 2005;24(3):283-307.

672 56. Williams AM, Janelle CM, Davids K. Constraints on the search for visual information in sport. Int J Sport Exerc Psychol 2004;2(3):301-18.

674 57. Williams EL, Jones HS, Andy Sparks S, Marchant DC, Midgley AW, Mc Naughton LR.

675 Competitor presence reduces internal attentional focus and improves $16.1 \mathrm{~km}$ cycling time trial 676 performance. J Sci Med Sport 2015;18(4):480-5. 


\section{Figure Legends}

Figure 1. Overall time-trial performance (A) and time-trial pacing by segment for familiarization (B) and time-trial $1(\mathrm{C})$.

Figure 2. Novice and Experienced total gaze duration data (A) and average gaze frequency (B) for primary (most looked at) through to nonary (least looked at) information sources calculated over the full $16.1 \mathrm{~km}$ distance for time-trial 1 (A) The type of information looked at with the corresponding number of subjects is presented alongside the data points in $2 \mathrm{~A}$ for primary to tertiary sources but not included for quaternary to nonary sources. * denotes $\mathrm{P}<0.05$; ** denotes $\mathrm{P}<0.01$; *** denotes $\mathrm{P}<0.001$.

Figure 3. Experienced versus novice segment-by-segment time-trial 1 total gaze duration data for primary (A), secondary (B) and tertiary information sources (C). * Denotes $\mathrm{P}<0.05$; ** denotes $\mathrm{P}<0.01$; *** denotes $\mathrm{P}<0.001$; NS denotes not significant.

Figure 4. Experienced versus novice segment-by-segment time-trial 1 average gaze frequency for primary (A), secondary (B) and tertiary information sources (C). * Denotes $\mathrm{P}<0.05$; ** denotes $\mathrm{P}<0.01$; *** denotes $\mathrm{P}<0.001$; NS denotes not significant. 


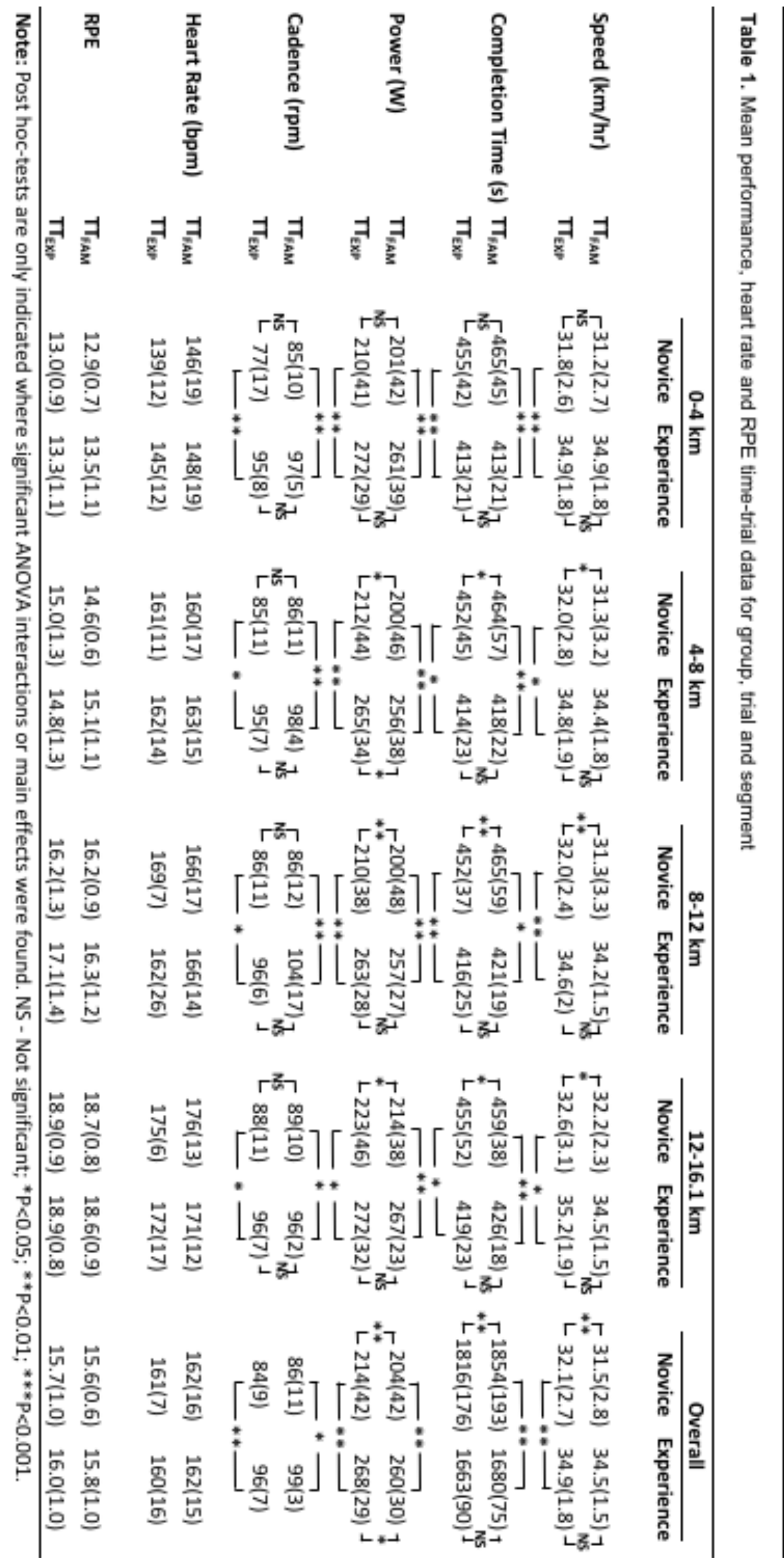


Table 2. Individual gaze combinations of primary and secondary information sources.

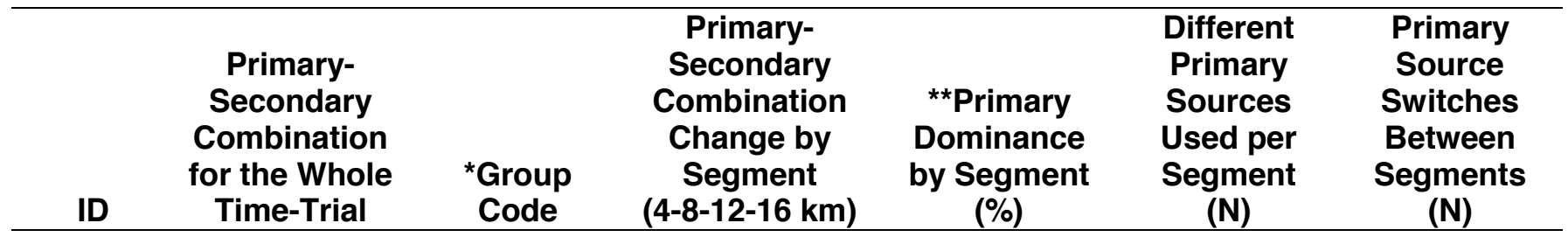

\section{Novices}

\begin{tabular}{cccc}
\hline S13 & DS & & SD-DS-DS-PD \\
S3 & DS & 1 & DT-DP-DS-DS \\
S8 & DS & & OV-DS-TS-DT \\
S10 & DO & 2 & CD-HD-OD-DO \\
S11 & DO & & DO-DP-DO-DO \\
S12 & DP & 3 & DP-DP-PD-DT \\
S7 & PD & 4 & DV-PT-PS-DS \\
S9 & SD & 5 & SD-SD-SO-SD \\
S6 & VD & 6 & DP-VO-VO-DO \\
S1 & TP & 7 & OT-PV-TP-DV \\
\hline Mean & & &
\end{tabular}

S.D.

Mode

DS

\#\#-\#\#-\#\#-DO

$\begin{array}{ccc}52-59-55-62 & 3 & 2 \\ 50-56-57-54 & 1 & 0 \\ 58-53-51-65 & 3 & 3 \\ 50-51-51-51 & 4 & 3 \\ 51-65-64-61 & 1 & 0 \\ 58-53-56-78 & 2 & 2 \\ 55-60-60-60 & 2 & 2 \\ 56-52-55-52 & 1 & 0 \\ 55-57-66-56 & 2 & 2 \\ 51-56-51-62 & 4 & 3 \\ 54-56-57-60 & \mathbf{2 . 3} & 1.7 \\ 3-4-5-8 & 1.2 & 1.3 \\ & 1 & 2\end{array}$

\section{Experts}

\begin{tabular}{|c|c|c|c|c|c|c|}
\hline $\mathrm{S} 24$ & SD & \multirow{5}{*}{5} & SD-SD-SD-SD & $61-62-64-64$ & 1 & 0 \\
\hline S25 & SD & & SP-SD-OD-SH & $50-50-52-52$ & 2 & 2 \\
\hline S26 & SD & & DS-DS-SD-SD & $54-52-62-71$ & 2 & 1 \\
\hline S30 & SD & & SO-SO-SD-SO & $66-62-58-61$ & 1 & 0 \\
\hline S32 & SD & & SD-SO-SO-SD & 64-64-70-66 & 1 & 0 \\
\hline $\mathrm{S} 22$ & SO & \multirow{2}{*}{8} & SD-ST-OS-SO & $78-79-59-53$ & 2 & 2 \\
\hline $\mathrm{S} 27$ & SO & & SD-SO-SO-SD & 69-57-70-59 & 1 & 0 \\
\hline S21 & SP & \multirow{2}{*}{9} & SP-SO-SP-DS & $65-65-72-51$ & 2 & 1 \\
\hline S28 & SP & & SP-SP-SO-SP & $68-61-68-69$ & 1 & 0 \\
\hline S23 & PS & 10 & PS-PS-PD-SH & $63-65-59-52$ & 2 & 1 \\
\hline Mean & & & & $64-62-63-60$ & 1.5 & 0.7 \\
\hline S.D. & & & & 8-8-7-8 & 0.5 & 0.8 \\
\hline Mode & SD & & \#\#-SO-SO-SD & & 1 & 0 \\
\hline \multicolumn{7}{|c|}{$\begin{array}{l}\text { Note - *Group code represents a specific combination of primary-secondary point of regard; **Dominance } \\
\text { of the primary point of regard is expressed as a percentage of the combined gaze time for both primary and } \\
\text { secondary points of regard. Primary-secondary point of regard combinations are represented by two letters, } \\
\text { with each single letter being coded as follows: } S=S \text { Speed; D-Elapsed DIstance; } P=P \text { Power; } C=\text { Cadence; } \\
\text { H=Heart Rate; T=Elapsed Time; R=Ratings of Perceived Exertion; } V=\text { =Projector Simulation View and } \\
\mathrm{O}=\text { Other. \#\# Indicating mode shared by more than one category }\end{array}$} \\
\hline
\end{tabular}



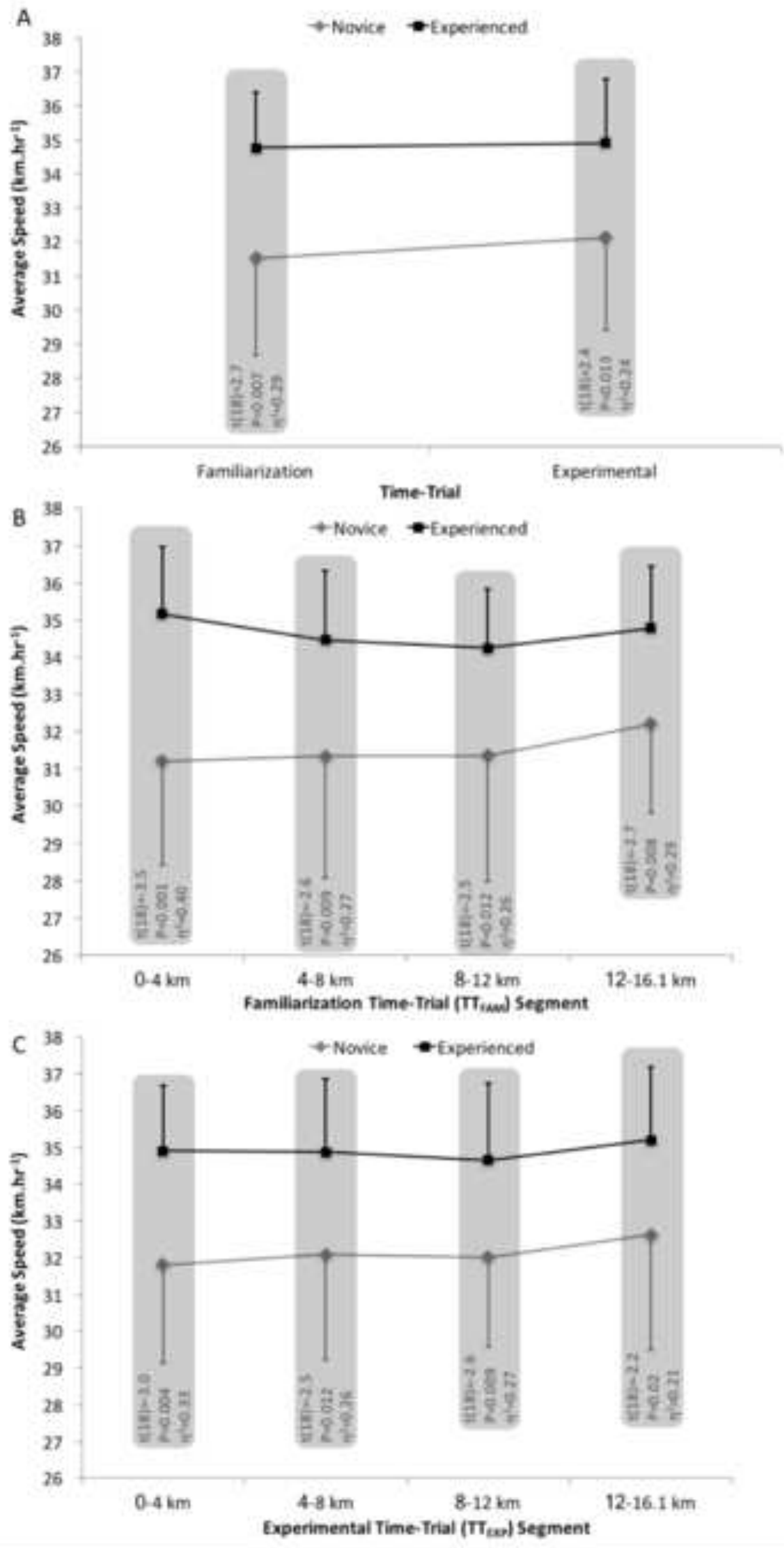

Figure 1. Overall time-trial performance (A) and time-trial pacing by segment for familiarization (B) and time-trial 1 (C). 

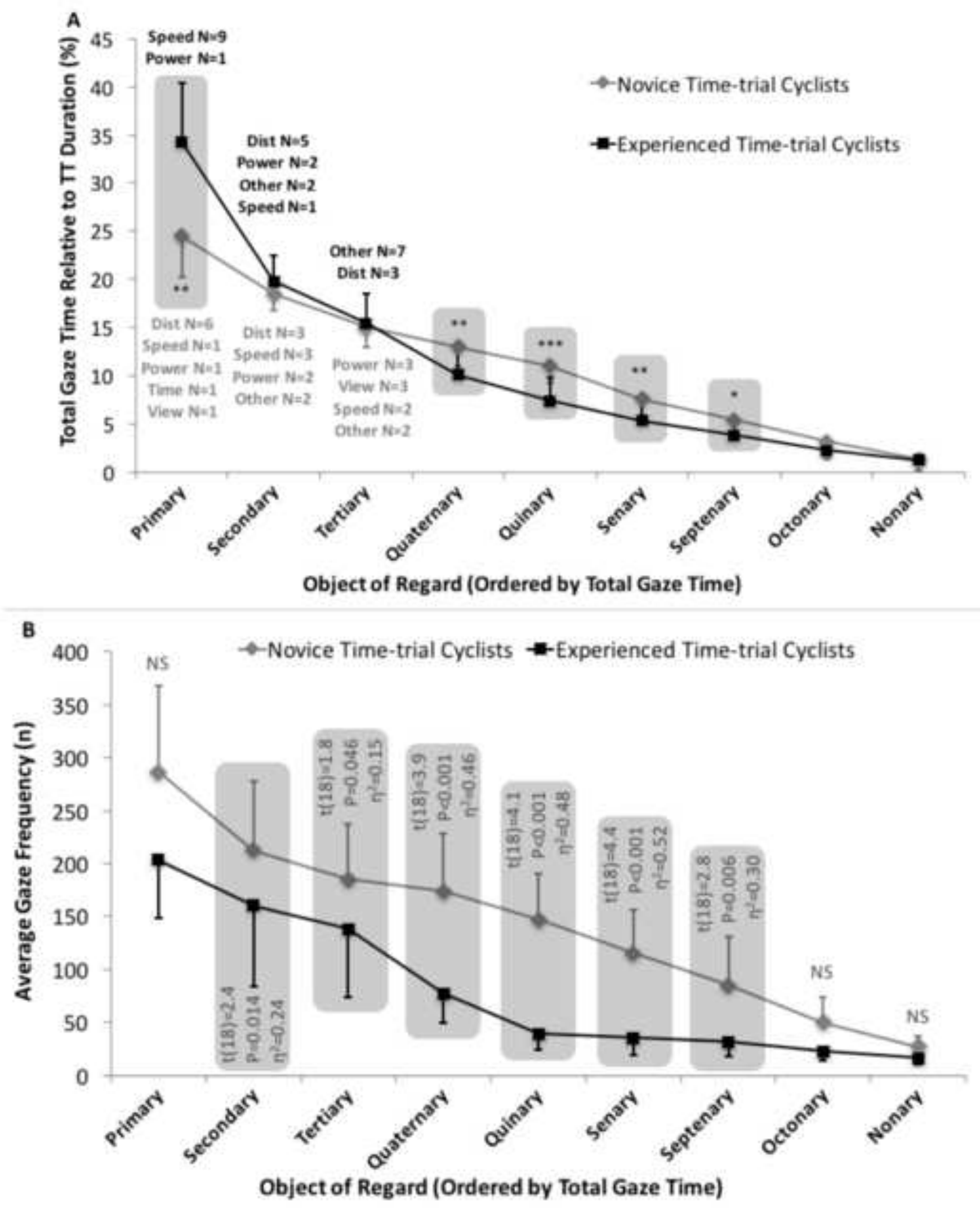

Figure 2. Novice and Expert total gaze duration data (A) and average gaze frequency (B) for primary (most looked at) through to nonary (least looked at) information sources calculated over the full $16.1 \mathrm{~km}$ distance for time-trial 1 (A) The type of information looked at with the corresponding number of subjects is presented alongside the data points in $2 \mathrm{~A}$ for primary to tertiary sources but not included for quaternary to nonary sources. * denotes $P<0.05 ; *$ denotes $P<0.01 ; * *$ denotes $P<0.001$. 


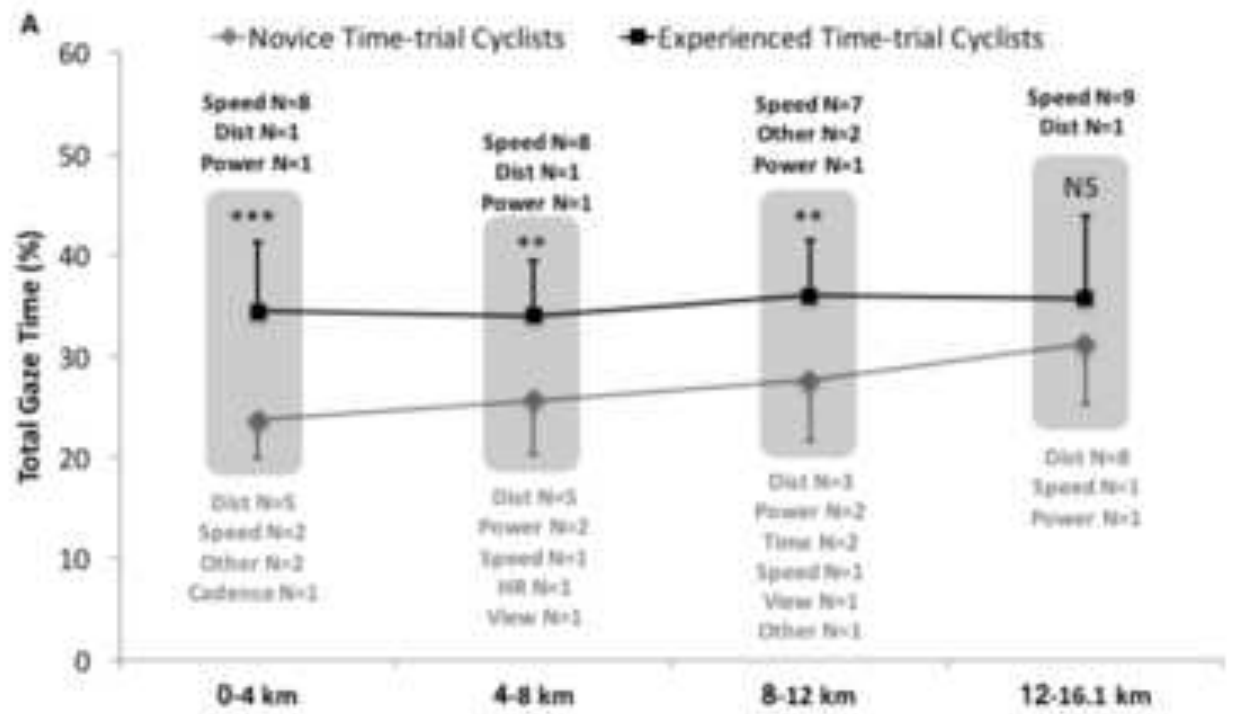

Time-Trial Segment

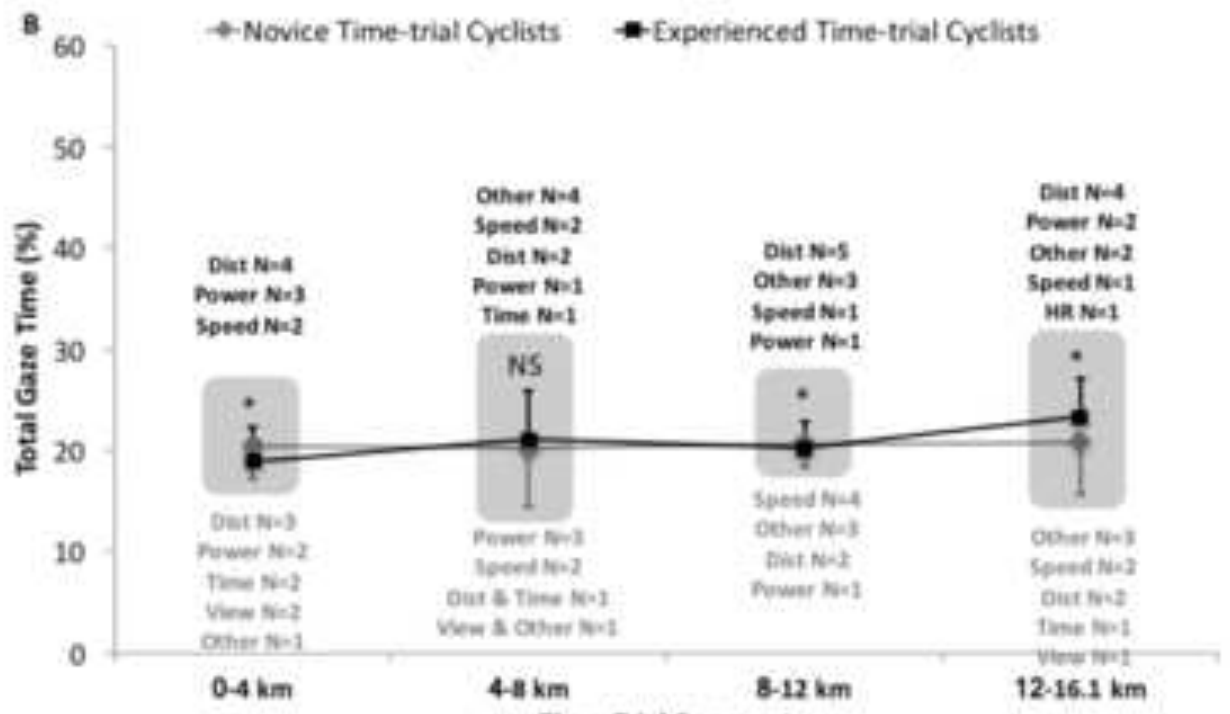

Time-Trial Segment

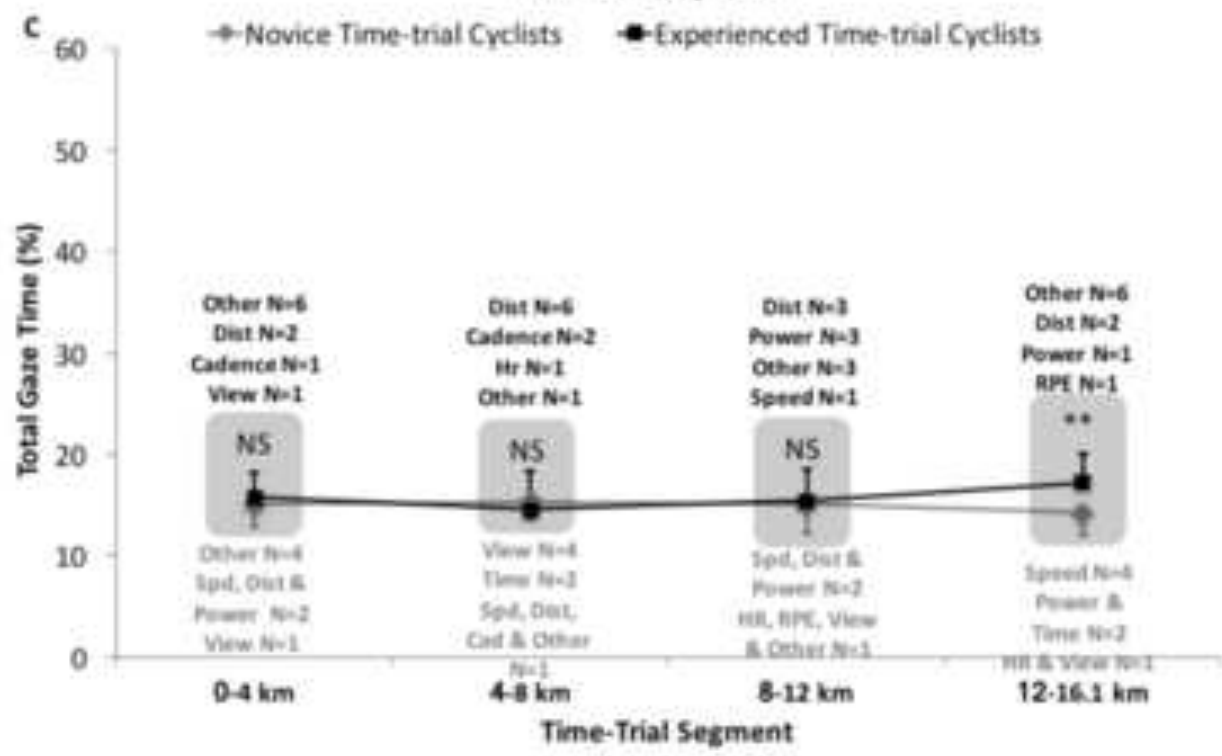

Figure 3. Expert versus novice segment-by-segment time-trial 1 total gaze duration data for primary (A), secondary $(B)$ and tertiary information sources $(C)$. * Denotes $P<0.05 ; \cdots$ denotes $P<0.01 ; \cdots$ denotes $P<0.001 ;$ NS denotes not significant. 

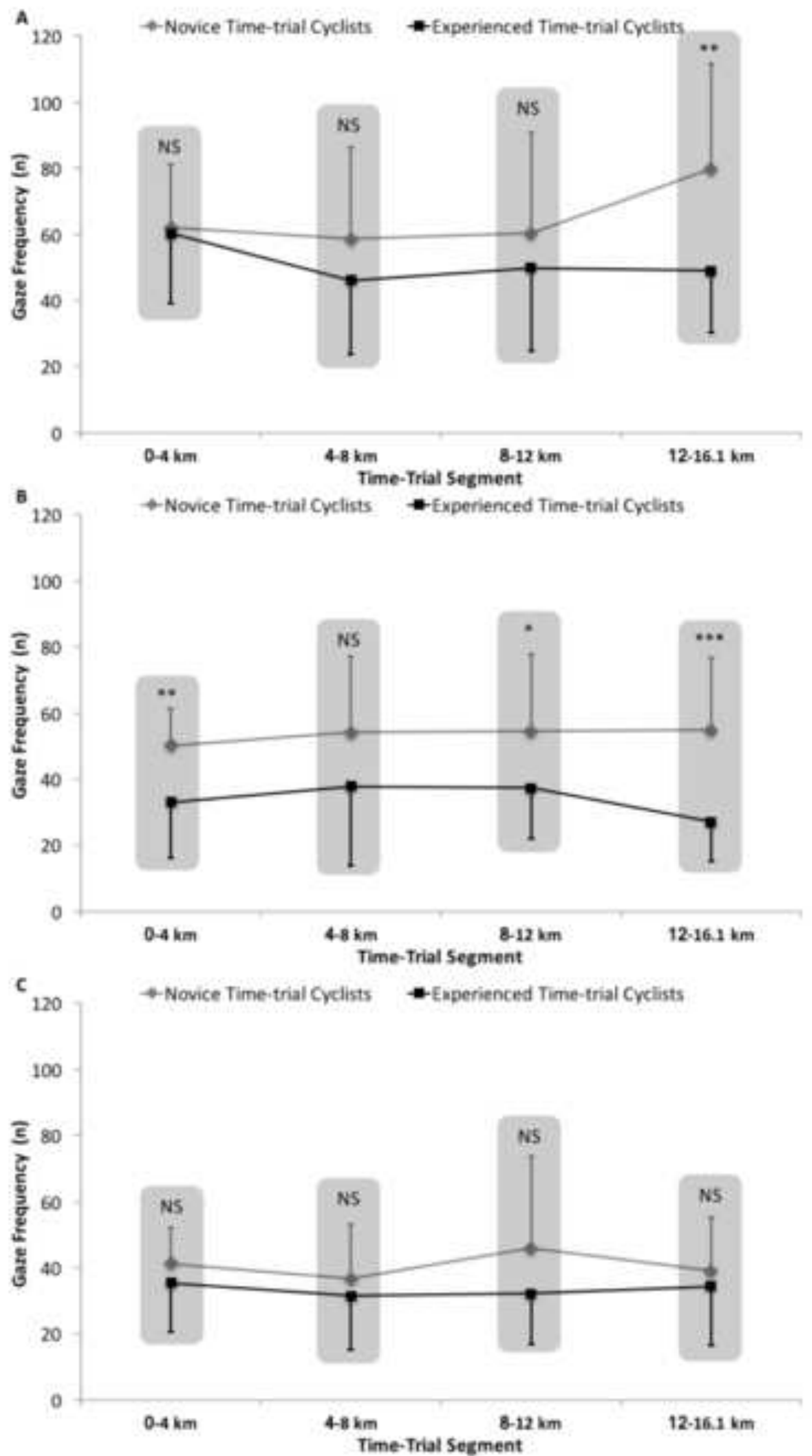

Figure 4. Expert versus novice segment-by-segment time-trial 1 average gaze frequency for primary (A), secondary $(B)$ and tertiary information sources $(C)$. * Denotes $P<0.05 ; \cdots$ denotes $P<0.01 ; \cdots$ denotes $P<0.001 ;$ NS denotes not significant. 